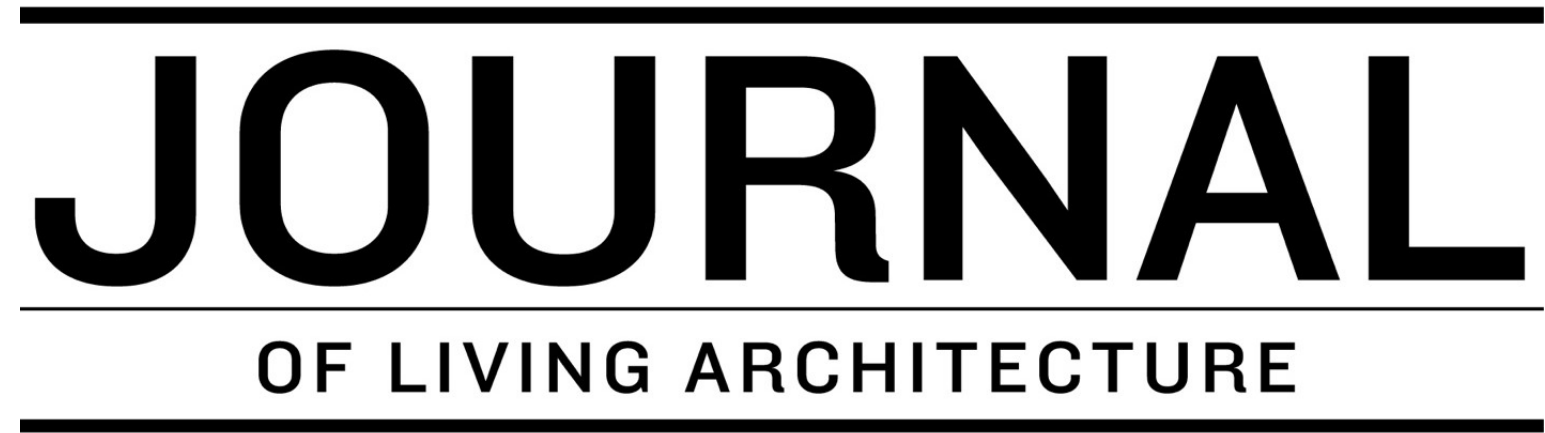

A GREEN ROOFS FOR HEALTHY CITIES PUBLICATION

Volume 6 Number 1 Pages 44-61

2019

\title{
Assessment of natural enemies for pest control on an indoor living wall
}

\author{
Susan Bjørnson ${ }^{*}$, Jay Gallant ${ }^{2}$ \\ ${ }^{I}$ Department of Biology, Saint Mary's University, Halifax, Nova Scotia, Canada \\ ${ }^{2}$ Gallant Interior Plants, Dartmouth Nova Scotia, Canada \\ *corresponding author: susan.bjornson@smu.ca
}

\begin{abstract}
Living walls are comprised of tropical plants that are susceptible to a variety of insect pests, but little information is available to help achieve effective pest control on vertical plant canopies. Although insect natural enemies can provide efficient pest control in indoor environments, the vertical canopies of living walls present challenges for natural enemy dispersal and success. During this six-month study, commercially-available natural enemies were released to control aphid outbreaks and a heavy infestation of soft brown scales on an indoor living wall. Three lady beetles were used: Lindorus (Rhyzobius) lophanthae (scale destroyer) and Cryptolaemus montrouzieri (mealybug destroyer) were released for scale control, and Adalia bipunctata (two-spotted lady beetle) was released to control aphids. Chrysoperla carnea (green lacewings) were released to observe natural enemy migration. Brown soft scale on Schefflera was reduced from 83.2 to 7.5 scales per leaflet (mid-May to mid-October; $91 \%$ reduction). C. montrouzieri was the only natural enemy able to establish itself on the wall, and their larvae were easy to monitor. Although the physical environment of the upper and lower canopies differed considerably, the natural enemies used were able to migrate freely and provide effective pest control.
\end{abstract}

Key words: Adalia bipunctata, biological pest control, Cryptolaemus montrouzieri, lady beetles, living wall

This peer-reviewed Article is provided free and open-access. 


\section{INTRODUCTION}

Living walls are becoming more commonplace in buildings where priority is given to environmental sustainability and green technologies. These vertical structures are comprised of surface vegetation for the purpose of enhancing the indoor work environment and improving air quality (Feng and Hewage, 2014; Brilli et al. 2018). Such claims are based on reports that certain indoor plant species, and the microbes associated with their roots, are able to reduce volatile organic compounds and other gaseous pollutants that arise from the offgassing of building materials, furnishings, and electronics, as well as chemicals from cleaning agents and other like compounds (Wolverton et al. 1989; Wolverton and Wolverton, 1993; Ghazalli et al. 2018; Torpy and Zavattaro, 2018). Moreover, the incorporation of plants in the local work environment provides various physical and psychological benefits to persons that are exposed to them, including reduced stress (Ulrich et al. 1991; Dijkstra et al. 2008), an increase in productivity for tasks that require concentration (Lohr et al. 1996; Chang and Chen, 2005), and an overall improvement in health (Ulrich, 1984, Weinmaster, 2009).

Because living walls are comprised of live plants, routine maintenance is required to retain aesthetic appeal. This includes the routine pruning of foliage and the provision of effective pest control. Because living wall technology is relatively new, little information is available regarding the types of pests that tend to colonize these walls or the means by which pest populations may be effectively managed. Insect pests on living walls can be problematic (Peck and Callaghan, 1999), but some have suggested they are of little concern as long as the wall canopy is composed of carefully chosen plant species that are otherwise maintained properly (Peck and Callaghan, 1999; Butkovich et al. 2008). Although nematodes are recommended for fungus gnat control in living wall substrates (Hum and Lai, 2007), for the most part, pest control on plant foliage has not been given serious consideration.

Commercially-available natural enemies provide effective pest control on various greenhouse crops (Pilkington et al. 2010) and on indoor plants where chemical pesticides cannot be used because of public health concerns. Common natural enemies include insect and arthropod predators and parasitic wasps. Many natural enemies are prey-specific and once released, they actively search for their preferred insect prey. Their efficacy depends upon correct identification of the insect pest or pests that are to be controlled. Once the pests are correctly identified, the appropriate natural enemies can be purchased from commercial suppliers for release directly onto plant foliage. Natural enemies must be released on a routine basis to build up numbers that are large enough to provide effective pest control. Routine monitoring of both natural enemies and pests provides the user with some reassurance that the pests are effectively being reduced, and enables one to quickly respond to new pest problems or localized pest outbreaks. Because natural enemies are susceptible to chemical pesticides, it is important to limit, or completely discontinue, the use of chemical controls prior to the adoption of natural enemies in any pest control program.

Recommendations have been made for the use of natural enemies for pest control on indoor plants within public spaces (Steiner and Elliott, 1983; Rebek and Schnelle, 2009). Potted 
plants are susceptible to many insect pests, including soft scales, aphids, thrips and spider mites. The canopies of such plants tend to occupy space within a rather localized area, and when individual plants are grouped together, they are often spaced so that their canopies are adjacent to one another laterally, where they experience similar environmental conditions. The vertical construction of a living wall, however, may create light and temperature gradients along the height of the entire canopy, from floor to ceiling. Plants in the upper canopy may be exposed to direct sunlight and solar heat during most of the daylight hours, but plants in the lower canopy may be subjected to far less exposure. Because many natural enemies thrive under a specific range of environmental conditions, this vertical distribution of plants could introduce sufficient challenges that may ultimately affect natural enemy efficacy, dispersal, and survival.

The aim of this study was to evaluate commercially-available natural enemies for augmentative biological control on an indoor living wall. The physical environment of the wall was assessed at the beginning of the study and a pest survey was used to determine the types of insect pests present. This information was used to determine the types of commercially-available natural enemies to be released. Natural enemies were monitored daily during the six-month study to assess efficacy, dispersal and survival.

\section{MATERIALS AND METHODS}

Installed in 2009, the living wall at Saint Mary's University (Figure 1) is the largest of its kind in Atlantic Canada. Located in the Atrium and Global Learning Commons, the wall is $7.6 \mathrm{~m}(25 \mathrm{ft})$ wide by $15.2 \mathrm{~m}(50 \mathrm{ft})$ in height at its central peak. Spanning three floors, the wall has a south-eastern exposure and is located directly beneath a ceiling that is comprised of alternating panels of clear and frosted glass. Two adjacent walkways ( $\sim \mathrm{m}$ in front of the wall surface) on each of the second and third floors are used for pedestrian traffic. Although it is a single, continuous structure, the two walkways artificially divide the living wall into three distinct regions: the lower (first floor), middle (second floor), and upper (third floor) canopies.

The living wall includes more than 1,000 individual plants, and more than 30 tropical plant species. The structure is soilless, with plumbing situated between two layers of proprietary, industrial-grade fabric that is made of coarse synthetic fibers. This fabric has sizeable pores and an uneven surface, with a texture similar to that of a scouring pad. Plants are embedded bare-root through incisions made in the upper layer of fabric. City water is pumped from the base of the wall to the upper canopy, where it flows downward over the plant roots that are confined between the two fabric layers, to the reservoir ('pit') at the base of the wall. The pit is filled halfway with fist-sized stones. City water is continually recirculated and replenished so that the water level in the pit remains flush with the upper surface of the stones.

This six-month study was undertaken from May to October 2012. Since their installation three years earlier, the wall plants were pruned routinely and insecticidal soap had been used in an attempt to manage soft brown scale. The upper canopy was dense with foliage, but 
much of it was coated in a thick layer of honeydew (sticky, sugary insect excrement that results from insect feeding) that caused adjacent leaves to stick together, and the growth of sooty mold. Sooty mold fungi on leaf surfaces is unsightly and excessive amounts may block sunlight and reduce photosynthesis (Tedders and Smith, 1976; Kaakeh et al. 1992). In contrast, almost one-third of the plants from the lower and middle canopies had died and many had been removed, leaving large gaps of exposed wall fabric. Those plants that remained had far fewer insect pests or honeydew. These barren wall areas were replanted during the latter half of the study period. Two interior living walls at neighboring institutions were examined so that comparisons could be made regarding plant species used, types of insect pests present, and overall differences in wall construction.

Because living walls are valued for their visual aesthetic, it was important for all remedial activities to be as unobtrusive as possible. Pests were monitored by examining foliage that was removed during regularly scheduled maintenance days, when dead and overgrown foliage were normally pruned. One month before the study began, the biweekly applications of insecticidal soap were discontinued. Natural enemies were released on days when plant maintenance was not scheduled. Water was applied weekly with a portable sprayer $(7.5 \mathrm{~L})$ to rinse honeydew buildup from foliage. A garden hose and high-pressure nozzle was used to carefully dislodge plant debris, salt residues, and moss from the wall fabric. A Genie vertical mast lift (Model GR-20, Genie Industries, WA) was used to access the upper canopy plants, whereas middle and lower canopy plants were readily assessible from their adjacent walkways with an extension ladder.

\section{Plant environment}

To better understand the physical environment of each plant canopy, $10 \mathrm{HOBO}$ data loggers (Onset Computer Corporation, MA) were used to collect local light, temperature and humidity data within each of the three canopies. These were positioned as follows: two on each side of the lower canopy ( $1.7 \mathrm{~m}$ and $2.4 \mathrm{~m}$ above the ground floor); two on each side of the middle canopy ( $0.4 \mathrm{~m}$ and $2.4 \mathrm{~m}$ above the second-floor walkway); and one on each side of the upper canopy ( $2.4 \mathrm{~m}$ above the third-floor walkway). The data box of each logger was attached directly to the stone tile wall surround with Velcro ${ }^{\circledR}$, and logger probes were positioned atop nearby foliage. Light (foot-candles; lumens $\left./ \mathrm{ft}^{2}\right)$, temperature $\left({ }^{\circ} \mathrm{C}\right)$ and relative humidity $(\% \mathrm{RH})$ data were recorded every $2 \mathrm{~min}$ for 2 to 3 days. Loggers were reset twice so that data were collected over a one-week period.

\section{Presence of insect pests}

An initial pest assessment was undertaken to determine the types of insects that were present and the severity of infestation on particular host plants. The information gained was used to determine which natural enemies were to be released. In order to determine insect pest presence, subsamples of foliage were examined from all of the plants that needed routine pruning from all three canopies. Pruned foliage was sorted according to plant species and 


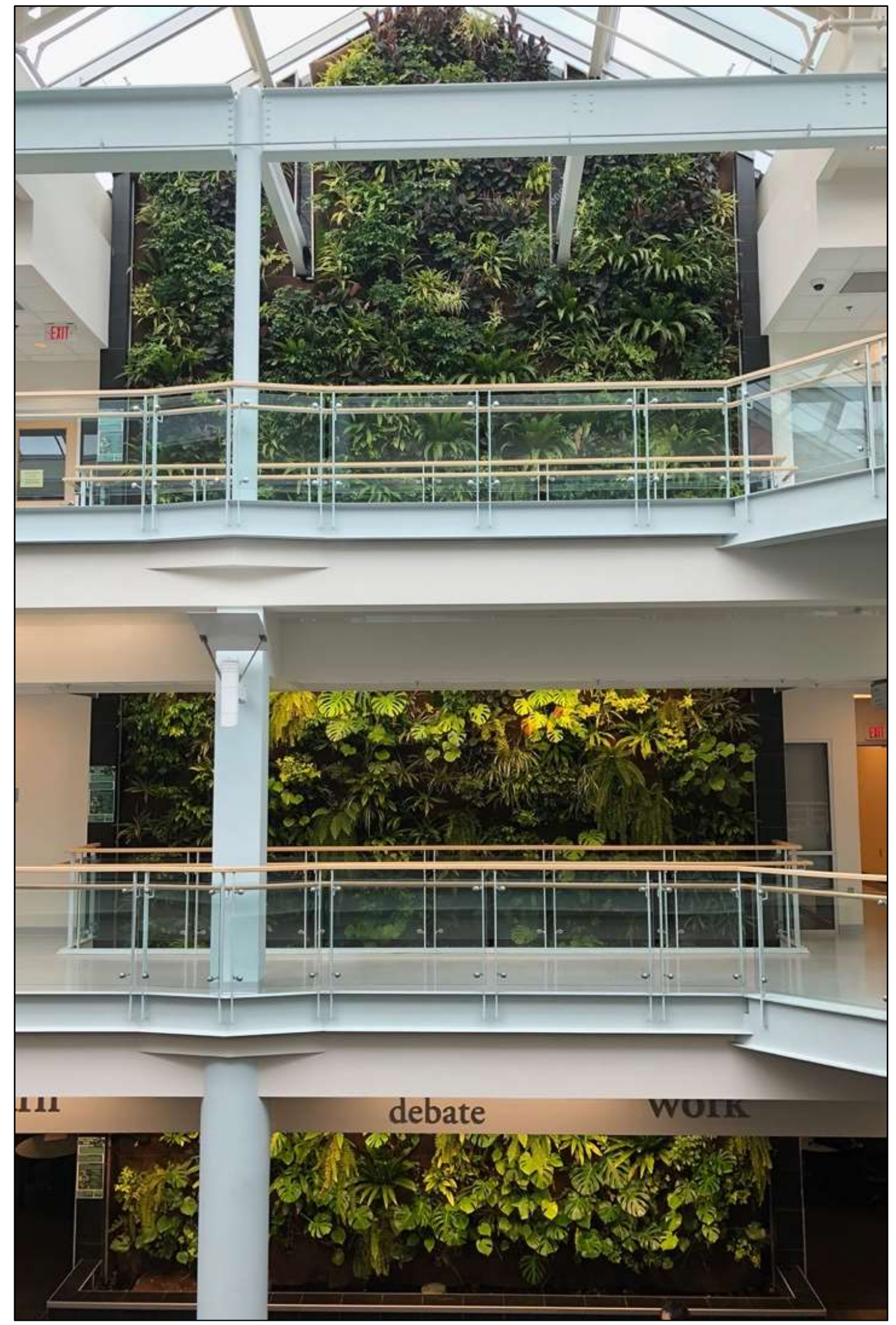

Figure 1 The living wall in the Atrium and Global Learning Commons at Saint Mary's University. 
canopy (lower, middle, upper), then stored at $5^{\circ} \mathrm{C}(24-48 \mathrm{~h})$ before examination (Zeiss stereomicroscope, 10-40X). The most abundant pests observed were soft brown scales and aphids, and localized infestations of spider mites were observed on palms. Although several plants were susceptible to insect pests, the dwarf umbrella plant, Schefflera arboricola, was the most heavily-infested. Therefore, only Schefflera foliage from the upper canopy was used to monitor insect pests for the remainder of the study. Schefflera foliage was collected on five additional occasions (during and after natural enemy releases), with three to four weeks between sampling dates. Soft brown scales were counted on randomly chosen Schefflera leaflets ( $n=20$ per sample date), and a linear regression was performed on pest data (Statistix 10) with time as an independent variable.

\section{Natural enemy releases}

Based on results from the initial pest assessment, four commercially-available natural enemies were released from late-May until early-August (Table 1). Three lady beetle species (Adalia bipunctata L., Cryptolaemus montrouzieri Mulsant, and Lindorus lophanthae Blaisdell) were released in the upper canopy where brown soft scale and aphids were most abundant. Green lacewing larvae, Chrysoperla carnea Stephens, were released on the lower and middle canopies to make observations on predator movement in areas where plants were sparse. Natural enemies were monitored daily for six months (late-May to late-October) by examining foliage that was along the length of the third-floor walkway. The predatory mite, Phytoseiulus persimilis Athias-Henriot was released for spider mite control on susceptible plants as required but was not monitored.

Each shipment of two-spotted lady beetles, A. bipunctata, consisted of 100 larvae packaged in shredded paper. On arrival, the package contents were redistributed among several 120-ml clear polyethylene cups. Each had a hole in the side that was covered with fine screen to allow air circulation. Just prior to release, the lid of each cup was removed and the entire cup was inserted into a second cup ('cup sleeve', see Figure 4d) that had been attached to the wall fabric with twist ties. Cup sleeves were positioned so that they were adjacent to plant foliage, allowing larvae to crawl directly from the cup onto nearby leaves. When aphid densities were high, a fine brush was used to place some of the larvae directly onto the foliage in high density ('hot spot') areas.

Shipments of green lacewings, C. carnea, consisted of 400 larvae packaged within individual cells of sealed, corrugated cardboard within a bubble envelope. Larvae were either released immediately or stored at $12^{\circ} \mathrm{C}$ for up to $48 \mathrm{~h}$ prior to release. Initial releases involved the 'cup sleeve' procedure outlined for A. bipunctata, but this proved time-consuming, and because $C$. carnea larvae are highly cannibalistic, the confinement of numerous larvae within a single cup was not ideal. Later releases involved direct placement of larvae on the canopy: about one-third of the mesh that covered the cardboard was peeled back from one side, and the cardboard was inverted atop a plant with broad, horizontal foliage. The cardboard was tapped lightly until the larvae fell onto the leaf surface. 
Table 1 Natural enemies released on the living wall at Saint Mary's University between late-May and early-August 2012.

\begin{tabular}{lllll}
$\begin{array}{l}\text { Natural Enemy } \\
\text { (common name) }\end{array}$ & $\begin{array}{l}\text { Stage } \\
\text { Released }\end{array}$ & Pest & $\begin{array}{l}\text { Location } \\
\text { Released }\end{array}$ & $\begin{array}{l}\text { Numbers and Dat } \\
\text { of Releases }\end{array}$ \\
\hline $\begin{array}{l}\text { Adalia bipunctata } \\
\text { (Two-spotted lady beetle) }\end{array}$ & Larvae & Aphids & Upper canopy & $\begin{array}{l}11 \text { releases* } \\
(2100 \text { larvae) }\end{array}$ \\
$\begin{array}{l}\text { Chrysoperla carnea } \\
\text { (Green lacewing) }\end{array}$ & Larvae & Generalist & Middle canopy & $\begin{array}{l}5 \text { releases** } \\
(1800 \text { larvae) }\end{array}$ \\
$\begin{array}{l}\text { Cryptolaemus montrouzieri } \\
\text { (Mealybug destroyer) }\end{array}$ & Adults & Brown & Upper canopy & $\begin{array}{l}1 \text { release*** } \\
(100 \text { adults) }\end{array}$ \\
$\begin{array}{l}\text { Lindorus lophanthae } \\
\text { (Scale destroyer) }\end{array}$ & Adults & $\begin{array}{l}\text { Brown } \\
\text { soft scale }\end{array}$ & Upper canopy & $\begin{array}{l}12 \text { releases* } \\
\text { (3250 adults) }\end{array}$ \\
\hline
\end{tabular}

* late-May to early-August; ** late-May to late-July; ***early-August

Shipments of 250 scale destroyer, L. lophanthae, adults were received in plastic vials with wood shavings. Early releases involved the 'cup sleeve' method, but later releases involved direct placement of beetles onto horizontal foliage of bird's nest fern (Asplenium nidus) where scale insects were abundant. In addition to L. lophanthae, mealybug destroyer adults, C. montrouzieri, were released once during the latter part of the study (mid-August), as a 'last resort' measure to control brown soft scale. One shipment of 100 adults was received in shredded paper in a plastic shipping box. Adults were removed on site by gently tapping each container until several fell onto nearby foliage. The open container was placed directly in the foliage to allow the remaining beetles to move into the canopy themselves. The broad and sturdy foliage of bird's nest fern and rubber tree (Ficus elastica) were particularly useful for such releases. Shipping containers were later removed from the wall and any remaining beetles were transferred onto foliage with a fine brush.

\section{RESULTS}

\section{Plant Environment}

Light intensity and temperature varied along the height of the wall (Figure 2). Although the light intensity at the base of the wall just above the pit $(1.7 \mathrm{~m}$ from the ground, lower canopy, left side) peaked at 128 foot-candles, it was most often between 1 and 100 foot-candles during daylight hours. Light levels in the middle canopy were higher than those on the lower level (generally between 100 to 400 foot-candles), and highest in the upper canopy, where daytime light intensity often peaked between 600 and 800 foot-candles. Because the minimum light intensity for photosynthesis is between 100 and 200 foot-candles (Chapman and Carter, 1976), the light intensity recorded on the lower canopy at ground level was deemed a limiting factor for plant growth. Supplemental lighting was added to the lower canopy walkway to increase light levels to a minimum of 100 foot-candles. Wall temperature was relatively moderate, ranging from about $15.5-21^{\circ} \mathrm{C}$ during evening hours and $20-27^{\circ} \mathrm{C}$ 
during the day for the three canopies. Relative humidity ranged from $25 \%$ in the evening to $35-50 \%$ during daylight hours.

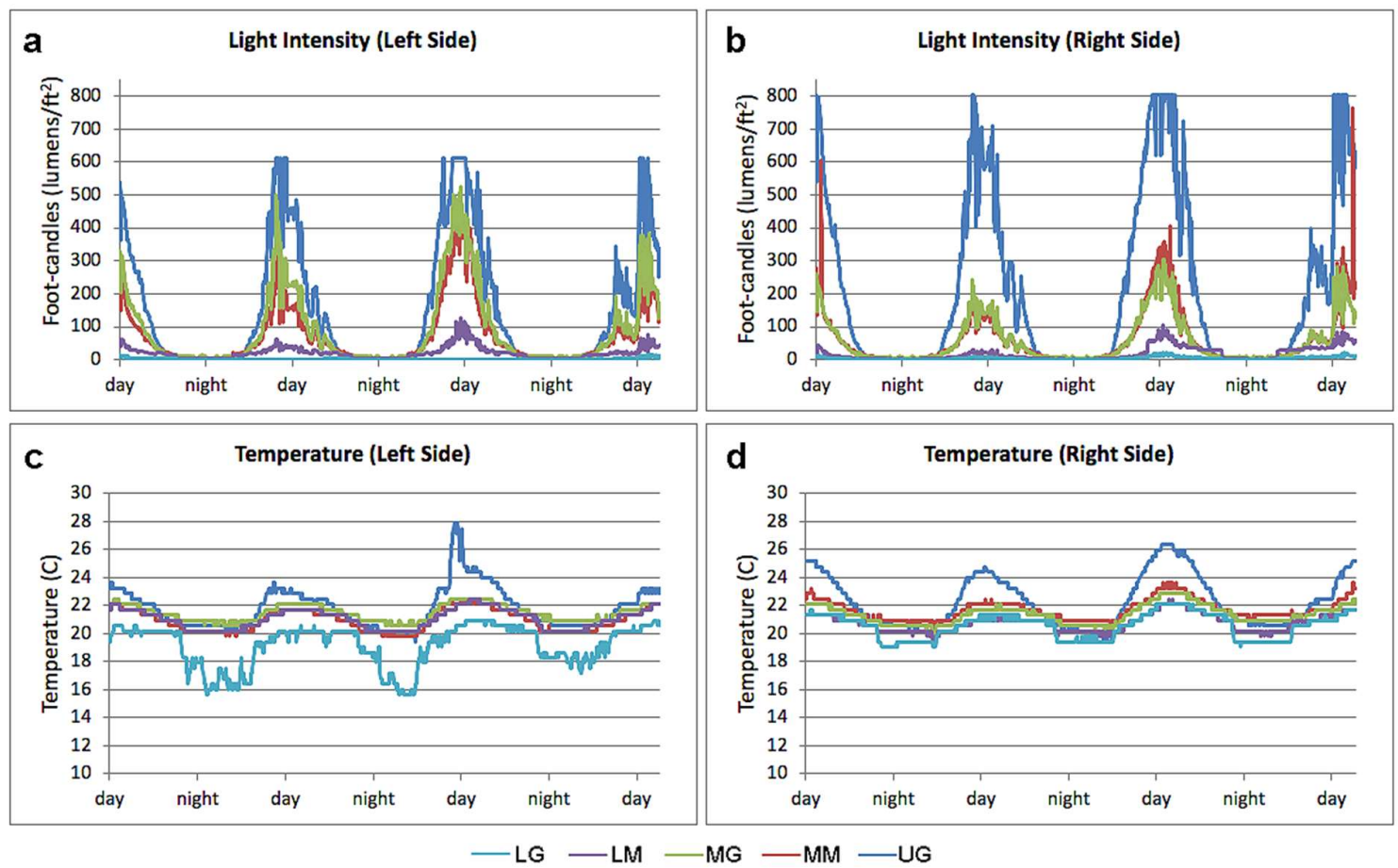

Figure 2 Examples of light intensity (foot-candles) and temperature $\left({ }^{\circ} \mathrm{C}\right)$ readings from the Saint Mary's University living wall over a 3-day period (04-07 May 2012). Figures a and b: variations in light intensity on the left and right sides of the wall, respectively. Figures $\mathrm{c}$ and d: variations in temperature on the left and right sides of the wall, respectively. Legend: LG (lower canopy, $1.7 \mathrm{~m}$ above ground floor), LM (lower canopy, $2.4 \mathrm{~m}$ above ground floor), MG (middle canopy, $0.4 \mathrm{~m}$ above 2nd-floor walkway), MM (middle canopy, $2.4 \mathrm{~m}$ above 2nd-floor walkway), UG, (upper canopy, $2.4 \mathrm{~m}$ above the 3 rd-floor walkway).

\section{Presence of insect pests}

The upper canopy had the greatest number of pests and pest damage, whereas the lower two canopies had far fewer pests but these were more diverse in their representation. The initial pest assessment revealed two primary insect pests on the upper canopy: the most abundant pest by far was brown soft scale (Coccus hesperidium L.; Figure 3a-c). Scale was prevalent on bird's nest fern, alii fig (Ficus maclellandii), and Algerian ivy (Hedera algeriensis; Table 2). However, the most heavily infested plant was the dwarf umbrella plant (Schefflera arboricola), which had been planted in abundance throughout the upper canopy. Due to the positioning of these plants, copious honeydew from insect feeding enveloped the upper canopy foliage and much of it was stuck together. The sheer abundance of scale on Schefflera was the reason why this plant was chosen to monitor brown soft scale throughout the study. Aphids were also a problematic pest on Schefflera (Figure 3d), where aphid feeding damage was localized and most evident on new growth. Emergent leaflets were either distorted or damaged completely (black, desiccated, remaining attached to the stem). Aphids were dark 
and minute, and difficult to monitor among the distorted new leaves. For the most part, aphids were observed indirectly by the presence of aphid exuviae, honeydew and black sooty mold (Figure 3e), and damaged Schefflera foliage. Although abundant, aphids fell off of the Schefflera leaflets once they were collected, and this made it difficult to make accurate counts. For this reason, aphid count data was not analyzed.

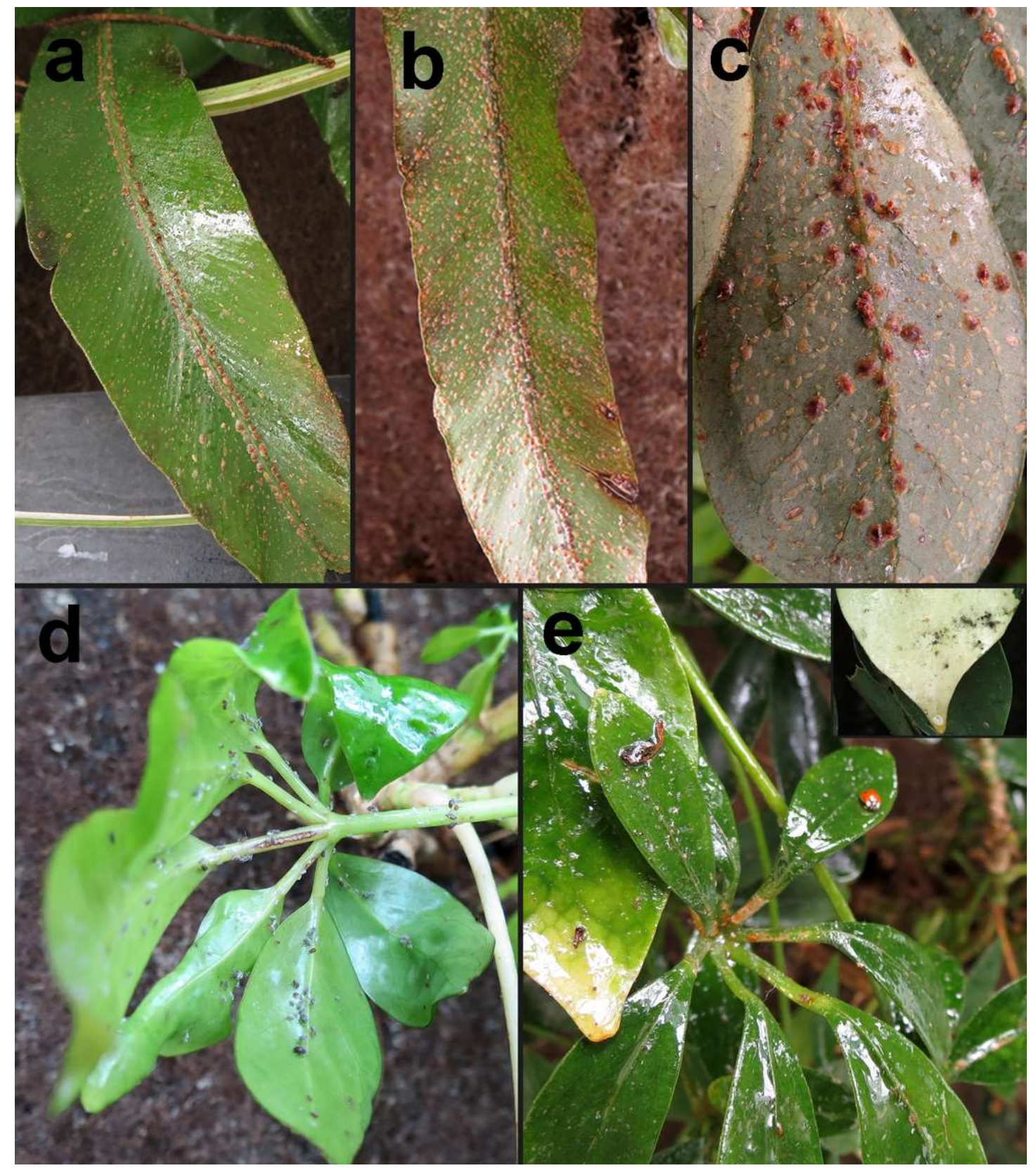

Figure 3 Insect pests and pest damage on the indoor living wall at Saint Mary's University. A severe infestation of soft brown scale along the midrib of the upper (a), and across the lower (b) foliage of bird's nest fern, Asplenium nidis, and (c) on the underside of an umbrella plant leaflet, Schefflera arboricola; (d), aphids on the underside of Schefflera foliage; (e), a thick coating of glossy honeydew (sticky insect excrement) and debris on the upper foliage of Schefflera, insert: black, sooty mold on leaflet. 
Spider mites (Tetranychus urticae Koch) were identified solely on the presence of their feeding damage, which was restricted to cat and neanthe bella palms (Chamaedorea cataractarum and C. elegans, respectively). Thrips were also observed on Schefflera at the beginning of the study. Neither the spider mites or thrips were monitored.

Table 2 Plants on the Saint Mary's University living wall according to canopy and pest susceptibility.

Latin Name

Asplenium nidus

Chamaedorea cataractarum

Chamaedorea elegans

Chlorophytum comosum

Codieaum sp.*

Dieffenbachia spp.*

Dracaena deremensis 'Janet Craig'

D. deremensis 'Janet Craig compacta'

Dracaena fragrans 'Lemon Lime'

D. fragrans 'Massangeana'

Dracaena marginata *

Dracaena reflexa 'Song of India' *

D. reflexa 'Song of Jamaica' *

Ficus benjamina

Ficus elastica

F. elastica 'Ruby' *

Ficus maclellandii

Ficus pumila

Hedera algeriensis

Hoya carnosa

Monstera delicosa *

Nephrolepsis cordifolia *

N. exaltata*

Philodendron cordatum

Philodendron friedrichsthalii

Philodendron hederaceum

Philodendron 'Imperial Green'

Philodendron selloum

Philodendron xanadu*

Platycerium bifurcatum *

Pteris sp. *

Schefflera arboricola

Spathiphyllum cochlearispathum

Syngonium podophyllum

Syngonium sp. *
Common Name

Bird's Nest Fern
Cat Palm
Neanthe Bella Palm
Spider Plant
Croton
Dumb Cane
Janet Craig Dracaena
Compact Janet Craig
Lemon lime dracaena
Corn Plant
Dragon tree
Song of India
Song of Jamaica
Weeping Fig
Rubber Tree
Ruby Rubber Tree
Alii Fig
Creeping Fig
Algerian Ivy
Wax Plant
Split Leaf Philodendron
Lemon Button Fern
Boston Fern
Sweetheart Plant
Swiss Cheese Plant
Heartleaf philodendron
Imperial Green Philodendron
Lacy Tree Philodendron
Xanadu Philodendron
Staghorn Fern
Silver Table Fern
Dwarf Umbrella Plant

\section{Distribution Pest(s)}

* Planted for the first time during the study period. $\mathrm{L}=$ lower canopy (first floor), $\mathrm{M}=$ middle canopy (second floor), $\mathrm{U}=$ upper canopy (third floor). 


\section{Natural enemy releases}

The initial pest survey gave focus to the upper canopy for remediation of soft scale and aphid infestations. A. bipunctata, C. montrouzieri and L. lophanthae were released onto wall plants adjacent to the third-floor walkway (upper canopy). Releases were made in the early morning. Natural enemies were monitored during the late afternoon so that any newlyreleased individuals had time to disperse from the release site before observations were made. A. bipunctata, C. montrouzieri and L. lophanthae were routinely observed during daily monitoring, and this provided evidence that at least some individuals had remained near (or returned to) the release site to provide localized pest control following release. C. carnea larvae and adults were also observed in this location, even though they were released in the lower and middle canopy only. This provided evidence that $C$. carnea larvae were able to span the rough wall fabric in areas where plant foliage was sparse.

A. bipunctata larvae, pupae, and adults were observed frequently on the upper canopy foliage during daily observation periods (Figure 4a), but eggs were not seen, suggesting that this natural enemy did not reproduce on the wall. Adults (two color morphs) were observed more often at the beginning of the study when aphids were present in large numbers, and less often during the latter part of the study as aphids became scarce. A. bipunctata adults that emerged during the latter part of the study were noticeably smaller than those observed earlier in the study. Larvae and pupae were seen at the top of the upper canopy nearest the glass ceiling, providing evidence that they were able to move effectively throughout the upper canopy.

Although C. carnea larvae were released on plants in the lower and middle canopies only, they were occasionally seen on foliage in the upper canopy (Figure 4b). This was impressive because at the time, the lower and middle canopies were sparsely planted, leaving large areas of exposed fabric and few plants to bridge the middle and upper canopies. Lacewing larvae are generalist predators and after they were found feeding on an A. bipunctata pupa (Figure 4b) and C. montrouzieri larvae, they were no longer released. Because lacewing larvae are cryptic, they were difficult to monitor. Adults are difficult to see when in flight and they tended to congregate toward the bright light at the top of the wall nearest the glass ceiling. As a result, $C$. carnea larvae and adults were seen infrequently and the numbers reported here are likely underrepresented.

Development of $C$. montrouzieri on the wall was self-perpetuating. Following the single release of adults in early-August, numerous cottony larvae and pupae were observed throughout the upper canopy until the end of October (Figure 4c). Larvae were able to crawl directly on the wall fabric and did not rely on overlapping plant foliage to move around. They occasionally became dislodged from upper canopy plants during maintenance (from leaf movement due to pruning or washing) only to end up in the pit area. Some larvae moved from the pit rocks onto the wall fabric and then onto lower canopy plants. Larvae and adults were observed with regularity. 

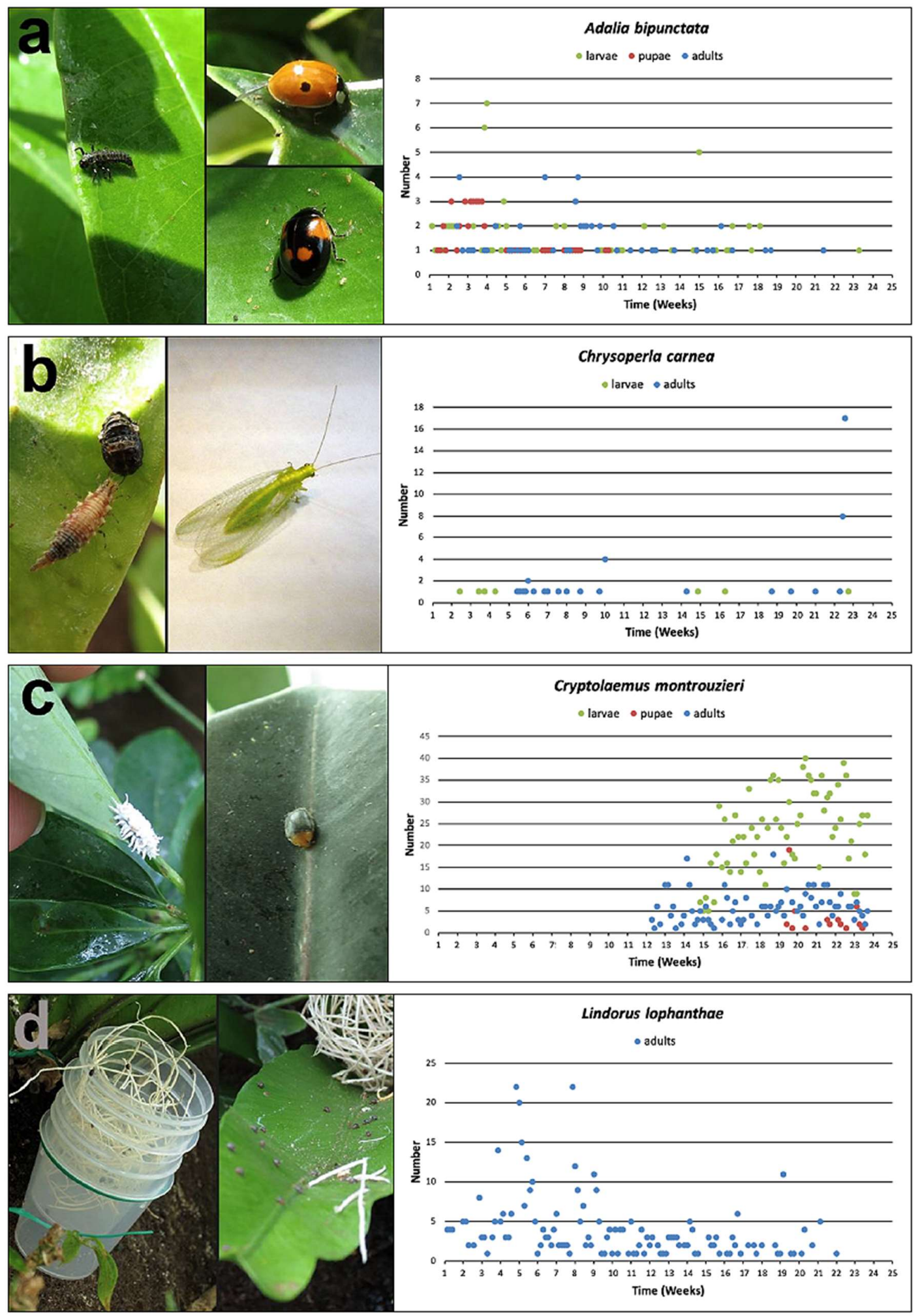

Figure 4 Natural enemies released and observed on the upper canopy of the living wall at Saint Mary's University alongside graphs that depict the abundance of life stages observed from late-May to late-October 2012. (a), two-spotted lady beetle (Adalia bipunctata) larva (left) and adult colour morphs (right); (b), green lacewing (Chrysoperla carnea) larva feeding on an A. bipunctata pupa (left) and adult (right); (c), mealybug destroyer (Cryptolaemus montrouzieri) larva (left) and adult 
(right); (d), scale destroyer (Lindorus lophanthae) adults and wood shavings within 'cup sleeve' and on foliage following dispersal.

L. lophanthae adults were unable to disperse on plant foliage that had a significant buildup of honeydew. Routine spraying of the foliage with water was necessary to ensure that these beetles did not stick to the foliage following release. The minute, dark adults were observed with some frequency (Figure 4d) but sightings diminished as the study progressed. Adults are small and dark, and were difficult to monitor. They were quite active and often flew away from the wall upon release. Larvae were not observed.

\section{Pest control}

During the study, brown soft scale decreased sharply on Schefflera in the upper canopy from an average of 83.2 scales per leaflet (mid-May) to 7.5 (mid-October; Figure 5). This $91 \%$ reduction was significant $\left(\mathrm{r}^{2}=0.41, \mathrm{~F}[1,118]=82.06, p<0.0001\right)$. L. lophanthae was effective at reducing the number of scale insects at the beginning of the study; however, the large number of scales that remained on Schefflera was a concern. C. montrouzieri is widely recommended for mealybug control, but because it is known to feed on some types of soft scale, a single shipment of adults was released in early-August as a 'last resort' measure. These adults produced larvae that quickly became abundant (Figure 4c) and during the latter portion of the study, C. montrouzieri began to proliferate, whereas Lindorus adults were seen with less frequency (Figure 4d). C. montrouzieri proved so effective for scale control that it was released exclusively for the management of this pest after the study ended.

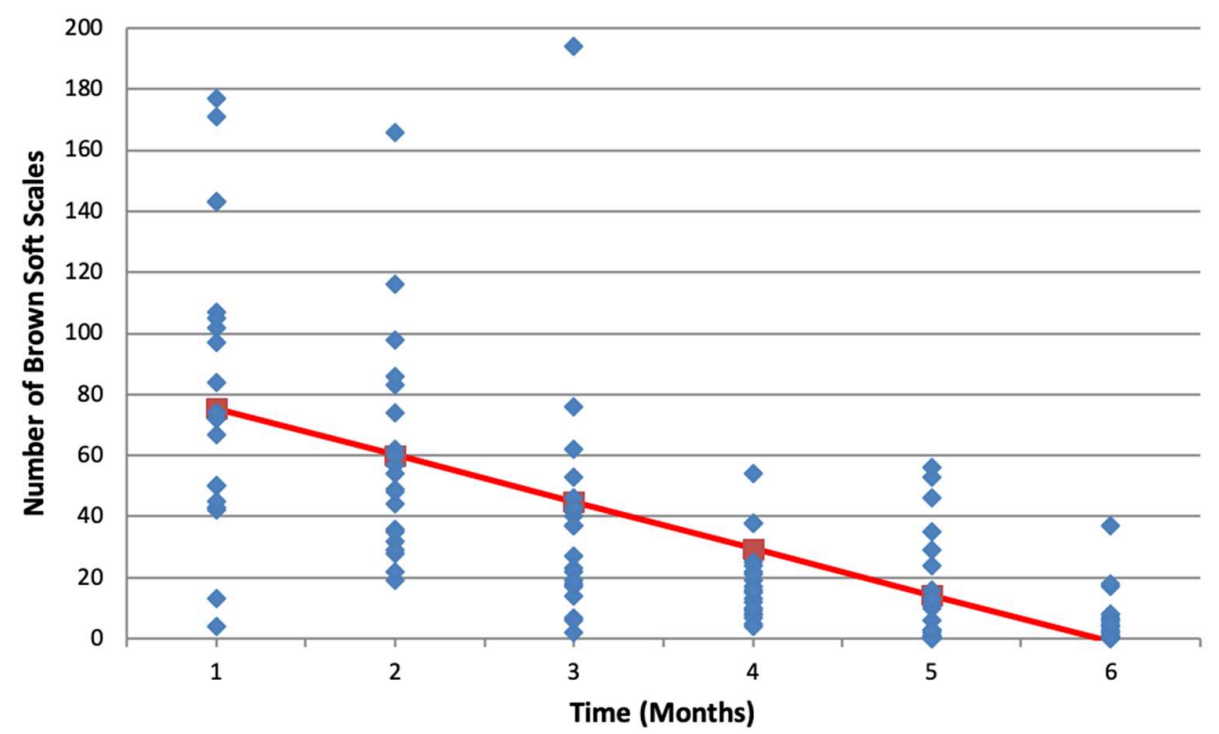

Figure 5 Brown soft scale on Schefflera arboricola foliage on the upper canopy of the Saint Mary's University living wall from late-May to late-October 2012. Linear regression: $\left(r^{2}=0.41, F[1,118]=\right.$ $82.06, p<0.0001)$.

Aphids were problematic at the beginning of the study, causing substantial damage to the new growth on Schefflera in the upper canopy. Although not quantified, periodic releases of A. bipunctata along the upper canopy walkway and on upper canopy hotspots were sufficient 
for aphid control in the upper canopy. As time progressed, aphid exuviae and plant damage were no longer observed.

\section{DISCUSSION}

Much of the published literature on living walls has focused on wall operations and the environmental benefits that these structures provide (Manso and Castro-Gomes, 2014; PérezUrrestarazu et al. 2015; Charoenkit and Yiemwattana, 2016). Insect pests are not given enough consideration on living walls because it is thought that pests prefer to remain on outdoor plants rather than to migrate indoors to populate living walls (Peck and Callaghan, 1999). However, it is important to recognize that indoor plants are not only susceptible to a variety of insect pests, but these are often present on foliage before the plants are installed. Under favorable growth conditions and with few control measures in place, insect pests are able to cause heavy infestations that when left unchecked, may create an unsightly mess and become difficult to control.

On the Saint Mary's University living wall, aphids and soft brown scale were far more abundant on upper canopy plants than on those in the lower two canopies. The large glass ceiling directly above the wall is likely a contributing factor toward the severity of infestation. Unlike the wall at Saint Mary's University, the two living walls at neighboring institutions were relatively thick with foliage. Visual examination of these wall canopies revealed low numbers of insect pests, including soft brown scale and aphids. Although these walls are smaller than the one at Saint Mary's University, and some of the plant species differed, these two structures were installed in areas with far less glass positioned directly overhead. This limited the amount of direct light that the plants received. Similarly, the lower two canopies of the wall at Saint Mary's University received limited light and even though the plants supported a variety of pests, their numbers were not large enough to produce excess honeydew or cause obvious feeding damage. Not only was the light in the upper canopy far brighter than in the lower two canopies, the temperature was noticeably warmer at the apex of the wall than it was along the third-floor walkway where loggers had recorded temperatures as high as $27^{\circ} \mathrm{C}$ during daylight hours. The higher light intensity and warmer temperatures contributed to robust foliar growth in the upper canopy. Unfortunately, these conditions also promoted a severe infestation of brown soft scale and copious honeydew through feeding. Scale infestations and excessive honeydew are known to affect photosynthesis of citrus and wheat (Rabbinge et al. 1981; Golan, et al. 2015), and the excessive honeydew on the foliage of the upper canopy likely caused similar stress, making these plants even more susceptible to insect pests.

Plant diversity is an important consideration for living walls because plant species composition can greatly influence pest populations in indoor environments. Diverse plantings are known to discourage pest outbreaks (Weinmaster, 2009; Wetzel et al. 2016), because it is more challenging for insect pests to relocate to other preferred host plants when these are spaced farther apart in a planting. Diverse plantings help slow the movement of pests within the canopy and limit insect feeding damage to localized areas that are less noticeable. For this 
reason, a diverse canopy may be visually and aesthetically more appealing than one that consists of only a few species.

Because most natural enemies thrive under a specific range of environmental conditions, the gradient and variation of light and heat along the height of the wall (Figure 2) raised concerns that the natural enemies used would not disperse throughout the canopy, but would rather move toward areas that best suited them following release. This was not the case for any of the natural enemies that were used. In particular, $C$. carnea larvae released on the middle canopy were able to ascend to the upper canopy, even when plant foliage was unavailable to them. Unfortunately, these larvae attacked other natural enemies, and this made them less than ideal for pest control in combination with the other natural enemies used. $C$.

montrouzieri larvae were relatively robust, and able to survive being dislodged from the upper canopy to the pit during maintenance, then migrate from the pit directly onto the wall fabric.

Augmentative biological control requires ongoing, periodic releases of large numbers of mass-reared natural enemies for the provision of effective pest control. The ability of a natural enemy to reproduce and become established following release can be cost-effective by reducing the number of releases that must be made over time. This was the case for $C$. montrouzieri. Shortly following release, numerous $C$. montrouzieri larvae were observed on upper canopy foliage, and the sharp contrast of the white, cottony larvae against the green foliage and brown wall fabric made them easy to monitor. These larvae are also easy to recognize by members of the university community, and signs adjacent to the wall provide information on the biology and importance of these (and other) natural enemies for indoor pest control. Today, several years after this study has ended, C. montrouzieri is the only natural enemy released for scale control on the living wall.

Although effective, L. lophanthae adults are tiny and were difficult to monitor. Sticky honeydew must be rinsed from foliage prior to release so that these beetles do not become stuck to the leaves. Although both L. lophanthae and C. montrouzieri provided effective scale control, C. montrouzieri adults did not get stuck in honeydew, they had larvae that were easy to monitor, and were able to reproduce on the wall. At the time of this study, L. lophanthae were the most expensive natural enemy released, at a cost of about \$1 CDN per beetle. The cost alone made L. lophanthae rather unattractive as a natural enemy, but even more so when these other factors were considered. Overall, brown soft scales were effectively reduced on Schefflera from 83.2 scales per leaflet in mid-May to 7.5 in mid-October. This reduction was significant, with $42 \%$ of the results attributed to the use of the natural enemies L. lophanthae and $C$. montrouzieri. The low $r$-value indicates that other factors were responsible for the reduced numbers of scale, and these could include the removal of leaves (with residual pests) during regular wall maintenance and the weekly application of water to rinse off excess foliar honeydew. Results suggest that the combination of augmentative biological control (natural enemies), along with various cultural controls (routine pruning of dead and overgrown foliage, foliar water rinses) were sufficient for controlling a heavy infestation of soft brown scale over a six-month period. 
Overall, the implementation of augmentative biological control for pest control has been slow, despite the widespread availability of many commercially-produced natural enemies (van Lenteren, 2012). To date, augmentative biological control has been widely used on greenhouse crops (Pilkington et al. 2010; van Lenteren, 2012), and in other areas where circumstances limit, or exclude, chemical pesticide use (Steiner and Elliott, 1983; Rebek and Schnelle, 2009). Because interior living walls are designed to reduce chemical pollutants from the indoor building environment, the application of chemicals for pest control directly conflicts with the purpose of these structures. However, living walls do provide new opportunities to implement and promote the use of natural enemies as a means of effective and ecologically sustainable pest control. Living walls are often located in high traffic areas where they showcase lush greenery for the purpose of enhancing the indoor work environment and improving air quality. The addition of clear signage in these public spaces can help educate the local community that in addition to providing various user benefits, an indoor wall represents a biological community that consists of plants, microbes, and both pest and beneficial insects.

\section{ACKNOWLEDGEMENTS}

We gratefully acknowledge the Natural Sciences and Engineering Research Council of Canada for funding (NSERC Engage Grant). We thank the Saint Mary's University community for their patience and feedback over the duration of this study, particularly those in Facilities Management that were directly involved with wall maintenance. Thanks to Tom Steele and Bryan Ellis for their technical assistance.

\section{LITERATURE CITED}

Brilli F., Fares, S., Ghirardo, A., de Visser, P., Calatayud, V., Muñoz, A., Annesi-Maesano, I., Sebastiani, F., Alivernini, A., Varriale, V., Menghini, F. 2018. "Plants for sustainable improvement of indoor air quality." Trends in Plant Science 23, 507- 512.

Butkovich, K., Graves, J., McKay, J., Slopack, M. 2008. "An investigation into the feasibility of biowall technology." George Brown College Applied Research \& Innovation. 26 pp.

Chang, C., Chen, P. 2005. "Human response to window views and indoor plants in the workplace." HortScience 40, 1354-59.

Chapman, S.R., Carter, L.P. 1976. Crop Production: Principles and Practices. W.H. Freeman \& Company, San Francisco. Pp. 146-163.

Charoenkit, S., Yiemwattana, S. 2016. "Living walls and their contribution to improved thermal comfort and carbon emission reduction: A review.” Building and Environment 105, 82-94.

Dijkstra, K., Pieterse, M.E., Pruyn, A. 2008. "Stress-reducing effects of indoor plants in the built healthcare environment: The mediating role of perceived attractiveness." Preventive Medicine 47, 279-283. 
Feng, H., Hewage, K. 2014. "Lifecycle assessment of living walls: Air purification and energy performance." Journal of Cleaner Production 69, 91-99.

Ghazalli, A.J., Brack, C., Bai, X., Said, I. 2018. "Alterations in use of space, air quality, temperature and humidity by the presence of vertical greenery system in a building corridor." Urban Forestry \& Urban Greening 32, 177-184.

Golan, K., Rubinowska, K., Kmieć, K., Kot, I., Górska-Drabik, E., Łagowska, B., Michałek, W. 2015. "Impact of scale insect infestation in the content of photosynthetic pigments and chlorophyll fluorescence in two host plant species." Arthropod-Plant Interactions 9, 55-65.

Hum, R., Lai P. 2007. Assessment of biowalls: An overview of plant- and microbial-based indoor air purification system. Physical Plant Services, Queen's University. 39 pp.

Kaakeh, W. Pfeiffer, D.G., Marini, R.P. 1992. "Combined effects of spirea aphid (Homoptera: Aphididae) and nitrogen fertilization on net photosynthesis, total chlorophyll content, and greenness of apple leaves." Journal of Economic Entomology 85, 939-946.

Lohr, V.I., Pearson-Mims, C.H., Goodwin, G.K. 1996. "Interior plants may improve worker productivity and reduce stress in a windowless environment." Journal of Environmental Horticulture 14, 97-100.

Manso, M., Castro-Gomes, J. 2014. "Green wall systems: A review of their characteristics." Renewable and Sustainable Energy Reviews 41, 863-871.

Peck, S.W., Callaghan, C. 1999. Greenbacks from green roofs: Forging a new industry in Canada. Canada Mortgage and Housing Corporation Report 82 pp.

Pérez-Urrestarazu, L., Fernández-Cañero, R., Franco-Salas A., Egea, G. 2015. "Vertical greening systems and sustainable cities." Journal of Urban Technology 22, 65-85.

Pilkington, L.J., Messelink, G., van Lenteren, J.C., Mottee, K.L. 2010. ““'Protected biological control” - Biological pest management in the greenhouse industry.” Biological Control 52, 216-20.

Rebek, E. and M. Schnelle. 2009. "Arthropod pest management in greenhouses and interiorscapes." E-1011, Oklahoma Cooperative Extension Service.

Rabbinge, R., Drees, E.M., van der Graff, M., Verberne, F.C., Wesselo, A. 1981. "Damage effects of cereal aphids in wheat." Netherlands Journal of Plant Pathology. 87, 27-232.

Tedders, W.L. Smith, J.S. 1976. "Shading effect on pecan by sooty mold growth.” Journal of Economic Entomology 69, 551-553.

Torpy, F., Zavattaro, M. 2018. "Bench-study of green-wall plants for indoor air pollution reduction." Journal of Living Architecture 5, 1-15.

Steiner, M.Y., Elliott, D. 1983. Biological pest management for interior plantscapes. Alberta Environmental Centre, Vegreville, Alberta. 32 pp. 
Ulrich, R.S. 1984. "View through a window may influence recovery from surgery." Science 224(4647), 420-21.

Ulrich, R.S., Simons, R.F., Losito, B.D., Fiorito, E., Miles, M.A., Zelson, M. 1991. "Stress recovery during exposure to natural and urban environments." Journal of Environmental Psychology 11, 201-230.

van Lenteren, J.C. 2012. "The state of commercial augmentative biological control: Plenty of natural enemies, but a frustrating lack of uptake." BioControl 57, 1-20.

Weinmaster, M. 2009. "Are green walls as "green" as they look? An introduction to the various technologies and ecological benefits of green walls." Journal of Green Building 4, 3-18.

Wetzell, W.C., Kharouba, H.M., Robinson, M., Holyoak, M., Karban, R. 2016. "Variability in plant nutrients reduces insect herbivore performance." Nature 539, 425-427.

Wolverton, B.C., Douglas, W.L., Bounds, M.S. 1989. A study of interior landscape plants for indoor air pollution abatement: An interim report. Report no: NASA-TM-108061. NASA Stennis Space Centre, USA. 14 pp.

Wolverton, B.C., Wolverton, J.D. 1993. "Plants and soil microorganisms: Removal of formaldehyde, xylene, and anomia from the indoor environment." Journal of Mississippi Academy of Sciences $38,11-15$. 